\title{
Saúde e envelhecimento: reflexões a partir do cenário sociodemográfico ${ }^{1}$
}

\author{
Marinês Tambara Leite*; Lúcia Hisako Takase Gonçalves **
}

\section{Resumo}

Este estudo tem por objetivo descrever e analisar o contexto sociodemográfico e de saúde da $17^{\underline{a}}$ Coordenadoria Regional de Saúde/Secretaria Estadual de Saúde/Rio Grande do Sul. O Brasil, nas últimas décadas, vem experimentando intensas mudanças em seu padrão demográfico, destacando-se o aumento do número de pessoas idosas no total da população. A queda das taxas de fecundidade e mortalidade e o aumento da longevidade são os fatores que contribuem para que haja incremento no envelhecimento populacional. Os aspectos relativos ao envelhecer são amplos e complexos, envolvendo questões pessoais e coletivas. Para isso, é importante estudar o espaço geográfico, sociodemográfico e de saúde, analisando os fatores que favorecem ou prejudicam a longevidade de uma determinada população. Com base nos dados relativos à demografia, analisaramse as modificações etárias que ocorreram nessa região. Em relação à saúde, a análise evidenciou que o sistema adotado nesse território segue a orientação do sistema brasileiro de saúde, com destaque para o
Sistema Único de Saúde, em que houve a reordenação das práticas sanitárias e da organização dos serviços. Identifica-se que a estrutura disponível para atender às demandas da população ainda é insuficiente, necessitando-se da adoção de diferentes formas de enfrentamento para a assistência, tratamento e reabilitação, além da implantação de políticas e ações preventivas e de promoção da saúde para toda a população, com vistas à promoção do envelhecimento ativo e saudável.

Palavras-chave: Idoso. Longevidade. Saúde. Demografia.

\section{Introdução}

O envelhecimento humano é resultado de diversos fatores, que, conjuntamente, contribuem para que as pessoas tenham uma vida longeva. Os determinantes sociais, econômicos, pessoais, comportamentais, ambientais e

* Enfermeira. Doutora em Gerontologia Biomédica pela Pontifícia Universidade Católica do Rio Grande do Sul. Professora do Departamento de Ciências da Saúde da Universidade Regional do Noroeste do estado do Rio Grande do Sul. Endereço para correspondência: Marinês Tambara Leite, Rua Floriano Peixoto, 776 , Centro, CEP 98700-000 Ijuí - RS. E-mail: marinesl@unijui.edu.br

** Enfermeira. Doutora em Enfermagem pela Universidade de São Paulo. Professora da Universidade Federal de Santa Catarina. Professora colaboradora do Programa de Pós-Graduação em Gerontologia Biomédica da Pontifícia Universidade Católica do Rio Grande do Sul (2001-2007).

1 Trabalho elaborado a partir da tese de doutorado "A equipe de enfermagem e sua interação com idosos internados em hospitais gerais”, apresentada ao Programa de Pós-Graduação em Gerontologia Biomédica da Pontifícia Universidade Católica do Rio Grande do Sul.

$\longrightarrow$ Recebido em junho de 2008 - Avaliado em março de 2009.

$\hookrightarrow$ doi:10.5335/rbceh.2009.018 
culturais, incluindo gênero, que envolvem indivíduos, famílias, comunidades e sociedades, contribuem para o envelhecimento populacional, que se pressupõe mais saudável que em outros tempos. (WHO, 2005).

Percebe-se que os aspectos relativos ao envelhecer são amplos e complexos. Assim, é importante caracterizar o espaço geográfico, sociodemográfico e de saúde, analisando os fatores que favorecem ou prejudicam a longevidade da população. O locus deste estudo é a região Noroeste do estado do Rio Grande do Sul, área de circunscrição da 17 Coordenadoria Regional de Saúde, demarcada pela Secretaria Estadual de Saúde, que congrega vinte municípios circunvizinhos e, aproximadamente, 225 mil habitantes. (IBGE, 2000). A densidade demográfica é próxima de trinta habitantes por quilômetro quadrado e possui o índice de desenvolvimento humano médio de 0,777 , que é inferior ao do estado, que é 0,814 , porém superior ao do Brasil, de 0,766.

Considerando esses aspectos, o presente estudo tem por objetivo descrever e analisar o contexto geográfico, socioeconômico e de saúde da $17^{\mathrm{a}}$ Coordenadoria Regional de Saúde/Secretaria Estadual de Saúde/Rio Grande do Sul.

$\mathrm{Na}$ região do estudo a formação social que deu origem à atual sociedade é relativamente recente - a partir do século XIX - e nela participaram, em especial, imigrantes europeus e seus descendentes, antecedidos pelos primitivos habitantes destas terras, os índios, e pelos luso-brasileiros e caboclos que já haviam iniciado a colonização do territó- rio, no início do século XIX. Essa composição étnica da população deu também origem às características socioculturais e econômicas da região.

Dentre as características da maior parte das etnias - italiana, alemã, polonesa e portuguesa - o trabalho com a terra era forte, pois não possuíam recursos financeiros para iniciar outra atividade, o que fortaleceu o vínculo dessa população com a atividade agropecuária, permitindo o desenvolvimento agrícola, modelo econômico predominante até a atualidade. Além disso, uma particularidade das famílias que aqui chegaram, ou que se formaram na época, era a de serem constituídas por um grande número de descendentes, nas quais as relações familiares eram valorizadas e reverenciadas como uma virtude nata, ou seja, havia forte coesão intrafamiliar, em que a interação entre seus membros é almejada e exercitada, atributo preservado até os dias atuais. (BRUM, 1998).

Nas palavras de Brum (1998), as particularidades, os valores, os traços culturais e a ideologia que presidiram hegemonicamente o processo histórico de colonização dessa região do estado, e que perpassam todas as atividades e a formação social, constituem-se dos seguintes aspectos: pequena propriedade agrícola; trabalho familiar, no qual todos os integrantes da família participavam; utilização intensiva dos recursos naturais, em especial a fertilidade do solo; prática da policultura; fé religiosa, como refúgio para as horas difíceis e fonte de renovação da esperança; forte coesão familiar; confiança na própria capacida- 
de; espírito de iniciativa para enfrentar e superar problemas e dificuldades; senso de comunidade, tendo dimensões políticas em função do bem comum da sociedade.

Em relação às condições de saúde da população residente na área de abrangência deste estudo e à forma como o sistema de saúde está organizado, visualiza-se que sua demografia se diferencia em comparação aos números do país. Considerando que os dados demográficos são também resultado de diversos fatores, como a redução das taxas de fecundidade, a diminuição dos índices de mortalidade infantil, o aumento da esperança de vida e o progressivo envelhecimento da população, vislumbram-se novos impactos e novas demandas para o sistema de saúde local.

Especificamente em relação à população idosa, os indicadores demográficos mostram, do mesmo modo, um cenário diferenciado ao se compararem os dados do país, que apresenta um percentual de idosos de $8,55 \%$ do total da população. O Rio Grande do Sul conta com 10,45\% e a região da $17^{\text {a }} \mathrm{CRS} / \mathrm{SES} / \mathrm{RS}$ possui uma taxa média de $11,47 \%$ da população com sessenta anos ou mais de idade, demonstrando uma diferença para mais de, aproximadamente, três pontos percentuais da região em relação ao país.
Ao olhar, nomeadamente, para cada um dos municípios, verifica-se que alguns possuem um maior percentual de idosos, particularmente Augusto Pestana $(15,28 \%)$ e Bozano (14,57\%), chegando a índices que o país, segundo estimativas, alcançará somente no ano de 2025. Essa realidade parece ser resultante não só do declínio da fecundidade, mas também do processo de urbanização, uma vez que houve significativa migração da população mais jovem para centros urbanos maiores, em decorrência da crise econômica, em busca de formação profissional e trabalho. Por sua vez, os pais e avós permanecem nos pequenos municípios, particularmente na área rural.

Conforme aponta Chaimowicz (1997), a redução da taxa de fecundidade deu-se não só pelo acesso ao sistema de saúde em busca de um adequado planejamento familiar, mas em virtude da urbanização da sociedade e da crise econômica brasileira, que, conjuntamente, agravam as condições de vida de famílias numerosas. Afirma ainda que a migração da população mais jovem "em direção aos grandes centros urbanos tende a agravar a situação social dos idosos ao afetar a configuração etária da população remanescente". (p. 185). Os dados podem ser observados na Tabela 1: 
Tabela 1 - Distribuição dos municípios de abrangência da 17ª CRS/SES quanto à população total e por faixa etária acima de sessenta anos de idade, 2006.

\begin{tabular}{l|r|r|r|r|r|r}
\hline \multicolumn{1}{c|}{ Município } & \multicolumn{1}{c|}{$\mathrm{N}$} & $60-69$ & $70-79$ & +80 & \multicolumn{1}{c}{ Idosos } & \multicolumn{1}{c}{$\%$} \\
\hline Ajuricaba & 7.464 & 595 & 331 & 109 & 1.035 & 13,9 \\
Augusto Pestana & 7.741 & 594 & 431 & 158 & 1.183 & 15,3 \\
Bozano & 2.188 & 159 & 84 & 76 & 319 & 14,6 \\
Campo Novo & 6.408 & 369 & 211 & 88 & 668 & 10,4 \\
Catuípe & 10.198 & 807 & 451 & 150 & 1.408 & 13,8 \\
Chiapetta & 4.481 & 235 & 171 & 50 & 456 & 10,2 \\
Condor & 6.539 & 404 & 230 & 93 & 727 & 11,1 \\
Coronel Barros & 2.454 & 270 & 121 & 49 & 440 & 17,9 \\
Crissiumal & 15.180 & 1098 & 624 & 270 & 1.992 & 13,1 \\
Humaitá & 4.754 & 336 & 211 & 82 & 629 & 13,2 \\
ljuí & 78.992 & 4.831 & 2.843 & 1.088 & 8.762 & 11,1 \\
Inhacorá & 2.378 & 149 & 83 & 39 & 271 & 11,4 \\
Jóia & 8.284 & 463 & 283 & 97 & 843 & 10,2 \\
Nova Ramada & 2.723 & 201 & 113 & 43 & 357 & 13,1 \\
Panambi & 34.633 & 1.803 & 1.128 & 418 & 3.349 & 9,7 \\
Pejuçara & 4.285 & 297 & 144 & 49 & 490 & 11,4 \\
Santo Augusto & 13.937 & 813 & 394 & 181 & 1.388 & 10,0 \\
São Valério do Sul & 2.625 & 163 & 71 & 47 & 281 & 10,7 \\
São Martinho & 5.696 & 395 & 221 & 100 & 716 & 12,6 \\
Sede Nova & 3.208 & 218 & 150 & 33 & 401 & 12,5 \\
Total & 224.168 & 14.200 & 8.295 & 3.220 & 25.715 & 11,5 \\
\hline
\end{tabular}

Fonte: Censo Demográfico, IBGE, 2000.

As taxas de fecundidade no estado do Rio Grande do Sul vêm decrescendo anualmente desde 1992, quando a média era de 2,3 filhos por mulher e, em 2002, atingiu 1,8 filho. Os resultados do Censo Demográfico do IBGE de 2000 (BRASIL, 2001) indicam que a taxa de crescimento populacional no Brasil, em relação a 1991, foi da ordem de 1,6\% ao ano.

Os dados do Rio Grande do Sul mostram, ainda, uma redução da razão de sexos à medida que aumenta a idade, evidenciando a tendência de sobremortalidade masculina em todos os grupos etários. No ano de 2004, do total de óbitos ocorridos no Rio Grande do Sul 56,15\% foram do sexo masculino e $43,85 \%$ do sexo feminino. Observa-se uma diferença de quase oito anos em termos de expectativa de vida ao nascer segundo o sexo: 77,4 anos para as mulheres e 69,2 para os homens. Esses números, confrontados com os da região da $17^{\text {a }} \mathrm{CRS} / \mathrm{SES} / \mathrm{RS}$, evidenciam que a expectativa de vida da população nela residente é maior, pois corroboram que, ao nascer, conforme o sexo, é de 79,2 anos para as mulheres e de 71,2 anos para os homens, perfazendo uma média de 75,1 anos para ambos os sexos. A CRS do Rio Grande do Sul é a que possui a maior expectativa de vida.

Esses são alguns aspectos do quadro demográfico da região de abrangência da $17^{\mathrm{a}}$ CRS/SES/RS. Nesse contexto há, 
ainda, os aspectos relativos à saúde, que se insere no sistema de saúde brasileiro, congrega o setor público, planos previdenciários e seguros privados de saúde. Conforme a Agência Nacional de Saúde Suplementar, os planos e seguros privados de saúde apresentam uma cobertura de $16 \%$ da população. $\mathrm{Na}$ organização desse sistema destaca-se o Sistema Único de Saúde, que preconiza a universalização do acesso, integralidade da atenção, equidade, descentralização da gestão, hierarquização dos serviços e controle social. O processo de implantação desse sistema pressupõe também a reordenação das práticas sanitárias e, em consequência, a transformação do modelo assistencial e da organização dos serviços. (BRASIL, 2001).

Atualmente, a totalidade dos municípios abrangidos por este estudo encontra-se habilitada em uma das condições de gestão estabelecidas pela Norma Operacional Básica ${ }^{1}$ - NOB/1996, que regula $o$ atual processo de gestão e descentralização dos sistemas de saúde, definindo o Programa de Agentes Comunitários de Saúde (PACS) e o Programa Saúde da Família (PSF) como estratégias de mudança do modelo assistencial.

Além desta, foi criada a Norma Operacional de Assistência à Saúde (NOAS) em 2001, que tem por objetivos definir o processo para a regionalização da assistência, atualizar os critérios de habilitação dos municípios e ampliar as responsabilidades na atenção básica. É com base nesta norma que os estados dividiram seu território em microrregiões de saúde, para garantir que a população tenha acesso a ações e serviços que não estão disponíveis em seus municípios o mais próximo possível de sua residência. Assim, do total de municípios circunscritos na região de abrangência da $17^{\mathrm{a}}$ CRS/SES/RS, 19 estão na condição de Gestão Plena da Atenção Básica Ampliada e somente um incorporou a Gestão do Sistema Municipal.

Esse quadro é semelhante ao encontrado em 99\% dos municípios e na totalidade das unidades da federação, uma vez que, do total de municípios brasileiros, em $200189 \%$ estavam na condição de Gestão Plena da Atenção Básica e 10\%, na de Gestão Plena do Sistema. Em relação aos conselhos municipais e estaduais de saúde - mecanismos de controle social -, também se encontram nacionalmente implantados. (BRASIL, 2001).

A progressiva adesão dos municípios ao PACS e ao PSF, como estratégia de atenção básica em saúde, é evidente. Os dados do Sistema de Indicadores da Atenção Básica (Siab) mostram que, em 1999 , de 29 a $100 \%$ da população residente nos municípios abrangidos pela 17 ${ }^{\text {a }}$ CRS/SES/RS tinham cobertura do PACS e somente dois (Ijuí e Sede Nova) contavam com um Programa de Saúde da Família. Já no ano de 2002, esses percentuais evoluíram para 48 a $100 \%$ da população com cobertura do PACS ou PSF. Em 2004, somente dois municípios (Santo Augusto e São Martinho) não haviam aderido ao Programa de Saúde da Família; os demais, gradativamente, foram implantando essa estratégia de atenção à saúde, sendo o PACS progressivamente agregado ao PSF, considerando os agentes comunitários de saúde como parte da equipe que compõe este progra- 
ma. Vale destacar que quatro municípios (Campo Novo, Coronel Barros, Inhacorá e São Valério do Sul) possuem $100 \%$ de sua população adstrita ao Programa de Saúde da Família.

Todos os municípios possuem conselhos municipais de saúde, que são órgãos deliberativos envolvendo setores da sociedade e técnicos, com o objetivo de formular estratégias de controle da política de saúde local, à semelhança do que ocorre com a maior parte dos municípios e na totalidade das unidades da federação. Salienta-se que nesses espaços estão incluídas as discussões relativas à assistência ao idoso, embora de forma pontual e, geralmente, quando há denúncias de não atendimento ou atendimento de saúde inadequado aos idosos.

Pesquisa realizada por Leite et al. (2003), sobre recursos assistenciais em saúde mental e gerontologia nos municípios de abrangência da $17^{\text {a }} \mathrm{CRS} / \mathrm{SES} /$ $\mathrm{RS}$, evidenciou que, em relação à pessoa idosa, os planos municipais de saúde não contemplam esta faixa etária especificamente; as informações e propostas de ações contidas nos planos relativas ao idoso, quando consideradas, estão diluídas em outras áreas, como a de saúde do trabalhador e do adulto. Nas situações de adoecimento, os idosos são atendidos nos hospitais gerais de seus municípios e, no caso de não possuir instituição hospitalar, são encaminhados para instituições de referência em município próximo. Isso quando a enfermidade não requer a utilização de recursos tecnológicos de maior complexidade. Quando da necessidade desses recursos, os pacientes são transferidos a instituições hospitalares de referência para a região ou mesmo no estado. Salienta-se que todos os municípios mantêm atividades de lazer e sociorrecreativas destinadas ao estrato populacional de idosos, as quais são desenvolvidas por meio de grupos operativos.

Em relação ao perfil de mortalidade, observa-se que a situação vem se modificando, com destaque para a queda dos óbitos infantis, a redução relativa das mortes por doenças infecciosas e o aumento daquelas decorrentes de doenças crônico-degenerativas. Em 2004 foram registrados 71.919 óbitos no Rio Grande do Sul. Desse total, 47.060 foram de pessoas com mais de sessenta anos de idade $(65,4 \%)$, das quais 17.235 foram de indivíduos com oitenta anos e mais, perfazendo um percentual de $36,6 \%$ do total de óbitos. Quando se observa a evolução do percentual de óbitos entre a população idosa no período compreendido entre 1980 (42,4\% do total das mortes) e $2004(57,4 \%)$, constata-se um aumento de, aproximadamente, dez pontos percentuais, dando a entender que há progressivo acréscimo no número de pessoas atingindo idades mais avançadas. Chama a atenção ainda o elevado percentual de óbitos entre as pessoas com mais de oitenta anos de idade, dando a entender que no Rio Grande do Sul há um significativo número de pessoas que atingem essa idade e, também, que nessa faixa etária os indivíduos apresentam maior fragilidade, vulnerabilidade e adoecimentos. (RIO GRANDE DO SUL, 2005).

Em estudo realizado sobre fatores associados às internações hospitalares no Brasil (COSTA et al., 2000), os 
resultados evidenciaram que o grupo etário de oitenta anos e mais de idade apresentou o maior coeficiente de internação, $18,7 \%$ do total. Deve-se atentar para essa situação em razão dos custos para o sistema de saúde, uma vez que a tendência é de que haja incremento na procura por serviços de saúde por essa população, os quais devem estar adequadamente organizados para atender a essa demanda. Chaimowicz (1997), ao abordar a saúde dos idosos brasileiros, menciona que os custos do sistema de saúde, mesmo nos países industrializados, tornam-se pesados, particularmente à medida que aumenta o percentual "muito velho" da população idosa, ou seja, indivíduos acima de oitenta anos de idade, que passam a consumir recursos desproporcionalmente maiores. Afirma, ainda, que duas linhas de ação podem ser adotadas para poder minimizar o impacto do envelhecimento populacional sobre o sistema de saúde e assistência social: a primeira seria ampliar a capacidade da rede de apoio formal e informal ao idoso e a segunda, buscar a redução da demanda ou compressão da morbidade.

Com tendência constante de queda, a mortalidade infantil atingiu no Rio Grande do Sul, em 2004, 15,1 óbitos por mil nascidos vivos, com maior participação do componente perinatal (18,7 por mil), ao passo que no ano de 1993 ocorreram 19,2 óbitos por mil nascidos vivos. Assim como no estado do Rio Grande do Sul, o declínio na mortalidade infantil ocorreu em todos os municípios de abrangência da $17^{\text {a }} \mathrm{CRS} / \mathrm{SES} / \mathrm{RS}$, com valores médios de 12,4 por mil. (RIO GRANDE DO SUL, 2005).
As estatísticas de saúde do Rio Grande do Sul mostram que, dentre as causas de morte no estado, as doenças do aparelho circulatório representam a principal razão $(30,8 \%)$, seguidas das neoplasias $(19,8 \%)$ e pelas doenças do aparelho respiratório $(12,2 \%)$. Os dados referentes à região da $17^{\mathrm{a}} \mathrm{CRS} / \mathrm{SES} / \mathrm{RS}$ são semelhantes, uma vez que as doenças do aparelho circulatório representam a principal causa $(33,3 \%)$ em todos os municípios, seguidas pelas neoplasias $(21,7 \%)$ e doenças do aparelho respiratório $(12,1 \%)$. Os dados, quando observados por faixa etária, particularmente entre aqueles com idade superior a sessenta anos, mostram que em 2004, no Rio Grande do Sul, as doenças do aparelho circulatório aparecem em primeiro lugar $(37,9 \%)$; na segunda posição, as neoplasias (20,5\%); na terceira, as doenças do sistema respiratório $(15,3 \%)$ e, na quarta posição, as doenças endócrinas e metabólicas $(6,0 \%)$.

No Rio Grande do Sul, entre os anos de 2002 e 2004 os indicadores evidenciam que houve um aumento na cobertura vacinal. As vacinas pólio oral BCG e tetravalente atingiram uma cobertura próxima de $100 \%$, enquanto que a tríplice viral foi de $87 \%$, tendência encontrada também nos municípios de abrangência da 17ª CRS/SES/RS. (RIO GRANDE DO SUL, 2005).

Com relação aos indicadores de morbidade e fatores de risco, destacase que, entre as doenças de notificação compulsória, as que apresentaram maior incidência em 2004 foram a hepatite viral, a leptospirose, outras meningites que não a meningocócica e a coqueluche. 
Foram computados 8.233 casos positivos de hepatite viral no estado, significando um índice de 7,6 casos por mil habitantes. A incidência de coqueluche teve significativa elevação no ano de 2004 (433 casos), em comparação com o ano de 2002 (141). O número de casos de leptospirose apresentou queda no ano de 2004 (2.144 ocorrências) em relação ao ano de 2002 (3.688).

Dos 2.957 nascimentos registrados em 2002, a maior concentração, por idade da mãe, correspondeu à faixa de 20 a 34 anos (70,0\%), sobressaindo-se também o alto percentual de mães entre 10 e 19 anos (17,0\%). A maior proporção de mães adolescentes foi observada no município de São Valério do Sul (30,0\%) e a menor, em Bozano (6,7\%).

Quanto aos recursos físicos em saúde, observa-se que a rede ambulatorial do SUS integra 125 unidades em 2003 , sendo $83,2 \%$ de natureza pública e $16,84 \%$ de natureza privada. $O$ setor público predomina em todo o país, com participação bem acima da média na região Norte (88\%) e inferior no Sul (66\%). Já em relação à rede hospitalar, o Brasil conta com 486 mil leitos em hospitais vinculados ao SUS, representando 2,8 por mil habitantes. Do total, $65 \%$ estão em hospitais da rede privada, $26 \%$ em instituições públicas e 9\% em universitárias. Entre 1996 e 2001, houve redução no número total de leitos - o que vem ocorrendo ininterruptamente ao longo da década de 1990 e mostra coerência com a diretriz de mudança no modelo assistencial. (BRASIL, 2006a). Em relação a este dado na região da $17^{\mathrm{a}} \mathrm{CRS} / \mathrm{SES} / \mathrm{RS}$, identifica-se que, em sua totalidade, há 3,5 leitos para cada mil habitantes (Tab. 2 ), porém nem todos os municípios possuem instituição hospitalar, talvez por serem recentemente emancipados ou em virtude de ser inviável sua manutenção em razão do número de habitantes versus capacidade ocupacional. 
Tabela 2 - Distribuição dos hospitais localizados nos municípios de abrangência da 17ª CRS/SES/ RS quanto à classificação e ao número de leitos, 2006.

\begin{tabular}{|c|c|c|c|}
\hline Classificação & Município: Hospital & N. & Leitos \\
\hline \multirow[t]{7}{*}{ Local } & Ajuricaba: Associação Hospitalar Beneficente Ajuricaba & 7.464 & 32 \\
\hline & Chiapeta: Sociedade Hospitalar Beneficente Chiapetta & 4.481 & 32 \\
\hline & Condor: Sociedade Hospitalar Beneficente Condor & 6.539 & 18 \\
\hline & Humaitá: Assoc. de Desenvolvimento Comunitário de Humaitá & 4.754 & 30 \\
\hline & Pejuçara: Casa Beneficente de Saúde Rio Branco & 4.189 & 21 \\
\hline & Santo Augusto: Soc. Hospit. Beneficente N. Senhora Aparecida & 13.937 & 30 \\
\hline & São Martinho: Sociedade Cultural São Gregório & 5.696 & 30 \\
\hline \multirow[t]{6}{*}{ Microrregional } & Augusto Pestana: Associação Protetora Hospital São Francisco & 7.741 & 40 \\
\hline & Campo Novo: Sociedade Hospitalar de Caridade Campo Novo & 6.408 & 30 \\
\hline & Crissiumal: Hospital de Caridade de Crissiumal & 13.620 & 58 \\
\hline & ljuí: Sociedade Beneficente Hospital Bom Pastor* & 78.992 & 35 \\
\hline & Panambi: Sociedade Hospital Panambi & 34.633 & 76 \\
\hline & Santo Augusto: Associação Hospitalar Bom Pastor* & 13.937 & 65 \\
\hline \multirow{8}{*}{$\begin{array}{l}\text { Regional } \\
\text { Municípios que } \\
\text { não possuem } \\
\text { hospitais }\end{array}$} & Ijuí: Associação Hospital de Caridade de ljuí & 78.992 & 230 \\
\hline & Bozano & 2.188 & \\
\hline & Catuipe & 10.198 & \\
\hline & Coronel Barros & 2.454 & \\
\hline & Inhacorá & 2.378 & \\
\hline & Jóia & 8.284 & \\
\hline & Nova Ramada & 2.723 & \\
\hline & Sede Nova & 3.208 & \\
\hline
\end{tabular}

Notas: * Dois hospitais nestes municípios. Obs.: Há, ainda, no município de Ijuí o Hospital Unimed, com setenta leitos, de natureza jurídica privada e que não mantém convênio com o Sistema Único de Saúde, sendo a única empresa deste gênero na região; iniciou suas atividades em abril de 2005, estando em processo de implantação, portanto não faz parte deste trabalho.

De certa forma, os municípios têm, por uma ou outra razão, seguido a normatização da política nacional, que visa reorganizar o modelo de saúde, centrando-se mais na atenção básica e no desenvolvimento de ações de baixa complexidade. Contudo, as ações realizadas ainda seguem o modelo biomédico, centrado na patologia, buscando, portanto, dar conta dos eventos mórbidos. Para que o município atenda ao que está pactuado nos princípios do Sistema Único de Saúde, deverá aumentar as ações de promoção da saúde, com ações de educação em saúde e de vigilância epidemiológica, realizar o acolhimento da demanda e exercer a clínica ampliada, no sentido de resolver os problemas de saúde, individuais e coletivos. Além disso, na clínica ampliada o objetivo é diagnosticar, mas, sobretudo, entender e formular políticas de saúde para a população. No que tange aos aspectos preventivos, as ações desenvolvidas relativas a imunizações, houve um baixo percentual de cobertura vacinal no ano de 2005, tendo sido de 68,8\%. (BRASIL, 2006b). 
Uma das formas de classificação desses hospitais é quanto à sua abrangência. O Ministério da Saúde os classifica como local, microrregional e regional. Assim, os hospitais de abrangência local têm como principais características serem hospitais gerais, especializados, pertencerem à esfera administrativa privada; serem entidades sem fins lucrativos e filantrópicos e, ainda, outros se constituindo como instituição privada lucrativa simples. Realizam internação de média complexidade e prestam atendimento ambulatorial e de emergência. Todos mantêm convênio com o SUS, atendem à demanda espontânea e referenciada nas especialidades de clínica geral, cirúrgica, obstetrícia, pediatria. Seu enquadramento no nível de hierarquia é média complexidade - M2 e M3 (estabelecimento de saúde que realiza procedimentos previstos nos níveis de hierarquia 02 e 03, além de procedimentos de média complexidade, abrangendo serviço de apoio à diagnose e terapia - SADT - e ambulatorial de média complexidade). (BRASIL, 2006a).

Por sua vez, as instituições hospitalares microrregionais possuem como características básicas: serem hospitais gerais, especializados; pertencer à esfera administrativa privada; serem entidades beneficentes sem fins lucrativos, filantrópicos, que realizam internação de média complexidade e prestam atendimento ambulatorial e de emergência. Conveniados pelo SUS, atendem à demanda espontânea e referenciada nas especialidades de clínica geral, cirúrgica, obstetrícia, pediatria. Além dessas, alguns mantêm atendimento em áreas como psiquiatria, ortopedia, traumatologia e nefrologia; outros, somente na área de psiquiatria. Seu enquadramento no nível de hierarquia é alta complexidade - M3 (estabelecimento de saúde que realiza procedimentos de média complexidade, além dos procedimentos previstos nos estabelecimentos nos níveis de hierarquia 2 e 3 , abrangendo SADT ambulatorial de alta complexidade). (BRASIL, 2006a).

A Associação Hospital de Caridade de Ijuí é a única instituição hospitalar de abrangência regional, especializada, geral, com esfera administrativa privada, sem fins lucrativos e filantrópica. A região de abrangência inclui as coordenadorias de saúde $9^{\mathrm{a}}, 12^{\mathrm{a}}, 15^{\mathrm{a}}, 17^{\mathrm{a}} \mathrm{e}$ $19^{a}$, representando uma população de 1.282 .927 pessoas, equivalente a $12,9 \%$ da população do estado, distribuída em 125 municípios. Serve de campo para a prática de ensino em diversas áreas do conhecimento. Realiza internação de média e alta complexidade, presta atendimento ambulatorial, de urgência e emergência. Tanto ambulatorialmente como nas internações hospitalares, atende nas áreas de clínica médica, clínica cirúrgica, pediatria, neurologia, ortopedia, obstetrícia, entre outras. Além dessas, possui diversos serviços de alta complexidade, como terapia renal substitutiva, litotripsia extracorpórea, transplante renal e de córnea, tomografia computadorizada, angiologia, dermatologia, endocrinologia, reumatologia, psiquiatria, cirurgia plástica, cirurgia de tórax, urologia, proctologia, hemoterapia, unidade de tratamento intensivo adulto e neonatal. 
Desde 2003, mantém o Centro de Alta Complexidade em Oncologia (Cacon). Mantém convênios com diversas empresas de seguro saúde. Constitui-se em hospital de referência terciária, população local e regional, sendo referência para dezenas de municípios. Conveniado pelo SUS, atende a demanda espontânea e referenciada. Realiza procedimentos previstos como alta HOS/AMB - estabelecimento de saúde que realiza procedimentos de alta complexidade no âmbito hospitalar e ambulatorial. (BRASIL, 2006a).

Retomando as questões dos hospitais, a quase totalidade deles possui somente equipamentos essenciais para atendimento básico. Quando necessário, os pacientes são encaminhados para outros serviços de referência, especialmente para a Associação Hospital de Caridade de Ijuí, o qual mantém aparelhamento radiodiagnóstico de alta tecnologia. Assim, quanto aos equipamentos em uso nos estabelecimentos de saúde, em 2005 havia uma distribuição diferenciada. Equipamentos de alta tecnologia existentes nos hospitais são reduzidos, como, por exemplo, o tomógrafo, que é ofertado somente por uma instituição hospitalar, a qual é referência para toda a região de abrangência da $17^{\mathrm{a}} \mathrm{CRS} / \mathrm{SES} /$ $\mathrm{RS}$, perfazendo 0,5 unidade por cem mil habitantes, ao passo que a oferta deste equipamento na região Sudeste do Brasil é de 1,3 unidade por cem mil habitantes e de 0,9 na média do país. No que diz respeito a máquinas para hemodiálise na região de abrangência do estudo, há uma média de 5,8 aparelhos para cada cem mil habitantes, enquanto que no Brasil existem, em média, 4,7 equipamentos de hemodiálise para cada grupo de cem mil habitantes.

A quase totalidade dos 2.957 partos realizados na região de abrangência da 17 ${ }^{\text {a }}$ CRS/SES/RS em 2002 ocorreu em hospitais $(99,6 \%)$, realizados pelo Sistema Único de Saúde e pelo segmento de planos e seguros privados. A proporção de partos cesarianos ainda é elevada $(52,3 \%)$, bem maior do que a taxa média do Brasil (38\%). Em relação à assistência pré-natal, aproximadamente metade das gestantes passou por sete e mais consultas de acompanhamento em 2002, com destaque para os municípios de Humaitá $(90,6 \%)$ e Ajuricaba $(86,2 \%)$ e, em menor proporção, o município de São Valério do Sul $(27,5 \%)$.

A transição epidemiológica que acompanha o envelhecimento populacional aponta para o aumento dos custos decorrente da alteração no padrão de morbidade. Enfermidades que acometem os idosos, geralmente, são crônicas e múltiplas, perduram por vários anos e exigem acompanhamento médico contínuo. (ASSIS, 2004). Além disso, conforme aumenta a proporção de idosos com idade avançada, eleva-se o percentual da população que sofre de enfermidades crônicas e incapacidades, determinando maior necessidade de recursos médicohospitalares para esse contingente, enquanto que os gastos da atenção a casos agudos se mantêm constantes.

Esse cenário já é pauta de preocupação, uma vez que no anexo da portaria $\mathrm{n}^{0}$ 1.395/GM, de 10 de dezembro de 1999, que trata da Política Nacional da Saúde do Idoso, consta que as modificações no 
perfil epidemiológico ocasionam elevados custos com tratamentos médicos, hospitalares e, concomitantemente, se configuram em um desafio para as autoridades sanitárias, particularmente no que se refere à implantação de novos modelos e métodos para o enfrentamento desse problema. Inclui ainda que a pessoa idosa consome mais serviços de saúde; as internações hospitalares são mais frequentes e o tempo de ocupação do leito é maior do que o de outras faixas etárias. Enfatiza que, em geral, as doenças que acometem os idosos são crônicas, múltiplas e perduram por vários anos, exigindo acompanhamento médico, equipes multidisciplinares permanentes e intervenções contínuas.

Informações relativas à internação hospitalar pelo Sistema Único de Saúde do ano de 1997, com base na população estimada pelo IBGE para esse ano, concluíram que o idoso consome muito mais recursos de saúde em comparação com outras faixas etárias. Naquele ano, o SUS arcou com 2.073.915 de um total de 12.715.568 de autorizações de internações hospitalares $(16,3 \%)$ destinadas para pacientes na faixa etária igual ou superior a sessenta anos de idade, ou seja, para $7,9 \%$ da população total. (BRASIL, 2006a).

Tabela 3 - Distribuição dos municípios/hospitais quanto ao número de internações total e o número de internações de pessoas idosas, 2006.

\begin{tabular}{l|c|c|c}
\hline \multirow{2}{*}{ Município } & \multicolumn{3}{|c}{2005} \\
\cline { 2 - 4 } & Internações & Internações de idosos & $\%$ \\
\hline Ajuricaba & 498 & 162 & 32,5 \\
Augusto Pestana & 465 & 228 & 49,0 \\
Campo Novo & 422 & 163 & 38,6 \\
Chiapetta & 348 & 112 & 32,2 \\
Condor & 335 & 110 & 32,8 \\
Crissiumal & 997 & 365 & 36,6 \\
Humaitá & 378 & 152 & 40,2 \\
ljuí & 8.713 & 2.564 & 29,4 \\
Panambi & 1.500 & 444 & 29,1 \\
Pejuçara & 222 & 86 & 38,7 \\
Santo Augusto & 2.135 & 599 & 28,1 \\
São Martinho & 397 & 168 & 42,3 \\
Total & 16.410 & 5.153 & 31,4 \\
\hline
\end{tabular}

Fonte: Brasil, SIH-MS, 2006b.

$\mathrm{Na}$ região deste estudo, tendo por base os dados registrados no Sistema de Informações sobre Autorização de Internações Hospitalares (SIH-MS), o número total de internações hospitalares, comparado com o número de internações de idosos, que em 2000 representava $12,30 \%$ da população da região, chama a atenção. Verifica-se que em 2005 esse grupo teve um percentual de internações que variou de $29,1 \%$ a $49,0 \%$, conforme pode ser visto na Tabela 3 , demonstrando a elevada procura deste segmento populacional pelos serviços 
de saúde hospitalar. No mesmo ano, do total de 16.410 internações 5.153 foram de pacientes com idade igual ou superior a sessenta anos, perfazendo um percentual de $31,4 \%$ do total de internações na região, percentual diferente do apresentado no estado do Rio Grande do Sul, uma vez que em 2005 o número total de internações foi de 735.157, sendo as de idosos 194.552, correspondendo a um percentual de $26,5 \%$ das internações. (BRASIL, 2006a).

$\mathrm{O}$ gradual aumento do número de internações hospitalares por parte da população idosa em nosso país constituise em uma realidade. Pesquisa de Costa et al. (2000) mostra que as demandas da população idosa por assistência à saúde são tão expressivas que 0 atendimento aos idosos já corresponde a $23 \%$ dos gastos públicos, no país somente com internações hospitalares.

Estudos de 1996 já evidenciavam que o coeficiente de hospitalização, ${ }^{2} 0$ índice de hospitalização $0^{3}$ e o índice de custo de hospitalizações do SUS $^{4}$ são mais elevados na faixa etária igual ou superior a sessenta anos de idade, quando comparada a qualquer outra faixa etária da população brasileira. Além disso, os índices de hospitalização e de custo hospitalar se elevam progressivamente após os sessenta anos e a ocorrência de reinternações entre os idosos é cinco vezes maior do que na faixa etária de 15-19 anos. (SILVESTRE et al., 1996).

Embora os custos com saúde sejam desproporcionais, uma vez que os idosos consomem mais, isso não quer dizer que o atendimento a essa parcela da população seja adequado em termos de recursos físicos e humanos. Essa situação se agrava, porque a maior parte dos custos é destinada à hospitalização, descentralizando o foco da promoção da saúde e da prevenção de agravos mórbidos. Cabe aos gestores e profissionais da saúde pensar em intervenções que possibilitem ao idoso o acesso a serviços adequados às suas necessidades, com o objetivo de prevenir e reduzir a carga de limitações, morbidades crônicas e mortalidade prematura; ainda, que permitam restringir os fatores de risco associados às principais doenças e aumentar os fatores que protegem a saúde durante a vida, enfim, constituir-se em serviço de saúde acessível, de alta qualidade e adequado para as pessoas que estão vivenciando a velhice.

\section{Considerações finais}

Algumas considerações podem ser retomadas ao término deste trabalho. Constata-se que a população da região estudada está envelhecendo num ritmo diferenciado daquela do estado do Rio Grande do Sul e do Brasil. Nessa região os idosos representam em torno de $12 \%$ do total. Isso significa dizer que o poder público de cada município deverá, mantidas as atuais tendências, estar preparado para enfrentar os desafios do envelhecimento antes mesmo que os governos estadual e federal.

Em relação à saúde da população residente na área de abrangência deste estudo e à forma como o sistema de saúde está organizado, visualiza-se que sua demografia se diferencia, quando comparada aos números do país. Considerando 
que os dados demográficos são também resultado de diversos fatores, como a redução das taxas de fecundidade, a diminuição dos índices de mortalidade infantil, o aumento da esperança de vida e o progressivo envelhecimento da população, vislumbram-se novos impactos e novas demandas para o sistema de saúde local.

Os dados permitem visualizar que a estrutura disponível para atender às demandas da população em todos os setores da atividade econômica, de educação e de saúde ainda é insuficiente. Portanto, vislumbram-se novos desafios a serem enfrentados para as próximas décadas, em especial no campo da saúde, pois, embora permaneça a ocorrência de doenças próprias da infância e de natureza aguda, concomitantemente, haverá morbidades resultantes, principalmente, de variáveis comportamentais, características do estilo de vida das pessoas, associadas ao aumento da expectativa de vida e ao mundo contemporâneo.

Tais informações apontam para a importância da adoção de diferentes formas de enfrentamento em termos não somente de assistência, tratamento e reabilitação, mas também, e principalmente, da implantação de políticas e ações preventivas e de promoção da saúde, para a população como um todo, com vistas à promoção do envelhecimento ativo e saudável. No que tange particularmente à população idosa, devem-se tomar medidas específicas de manutenção da autonomia e capacidade funcional e, ainda, implantação de estratégias de cunho preventivo, com o propósito da não instalação de disfuncionalidades, incapacidades, dependência e, por que não, a institucionalização.

Health and aging: reflexions from the social demographic scene

\section{Abstract}

This text is intended to describe and analise the demographic and health context of the $17^{\mathrm{a}}$ Coordenadoria Regional de Saúde/Secretaria Estadual de Saúde/Rio Grande do Sul. In the last decades Brazil is coming through several changes in its demographic pattern, emphasizing the grown in the number of elderly people in the population. The decrease in the fecundity and mortality taxes and the increase in the longevity are the factors that contribute to the improving of population aging. The aspects related to the aging are wide and complex, involving social and collective issues. For that, it's important to study the demographic space, social demographic and the health, analyzing the factors that benefit or damage the longevity of a certain population. Based in the data related to the demography, the changes in the age ranges that happened in this region were analyzed. Regarding the health, the analysis showed that the system adopted in this territory follows the orientations of the Brazilian health system, emphasizing the Sistema Único de Saúde (SUS), in what happened the rearrangement of the sanitarian practice and the organization of the services. Noticing that the structure available to assist the demands of the population is still not enough, the adoption of different forms to confront the assistance, treatment and rehab, besides the implantation of politics and preventive actions and promoting health, to the whole population, with the object to promote the active and healthy aging are needed.

Key words: Aging. Health. Demography. Longevity. 


\section{Referências}

ASSIS, M. Promoção da saúde e envelhecimento: avaliação de uma experiência no Ambulatório do Núcleo de Atenção ao Idoso da UnATI. 2004. Tese (Doutorado) - Escola Nacional de Saúde Pública da Universidade do Estado do Rio de Janeiro, Rio de Janeiro, 2004.

BRASIL. Anuário estatístico de saúde do Brasil. Fundação Sistema Estadual de Análise de Dados. Disponível em: <portal.saude. gov.br/portal/anuario2000>. Acesso em: $1^{\text {o }}$ nov. 2001.

Ministério da Saúde. Informações de saúde. Datasus. Disponível em: <tabnet. datasus.gov.br/cgi/deftohtm.exe?sih/cnv/ mirs.htm>. Acesso em: 1º nov. 2006.

. Portaria 1395/GM, de 13 de dezembro de 1999. Dispõe sobre a aprovação da Política Nacional de Saúde do Idoso. Diário Oficial da União, 1999.

. Programa Nacional de Imunizações. Informações em saúde. Secretaria Estadual de Saúde. Disponível em: <www.datasus. gov.br/informaçõesemsaude/>. Acesso em: 10 out. 2006.

BRUM, A. J. Unijuí - uma experiência de universidade comunitária: sua história, suas idéias. $2^{\text {a }}$ ed. Ijuí: Unijuí, 1998.

CHAIMOWICZ, F. A saúde dos idosos brasileiros às vésperas do século XXI: problemas, projeções e alternativas. Saúde Pública, São Paulo, v. 31, n. 2, p. 184-200, 1997.

COSTA, M. F. F. L. et al. Diagnóstico da situação de saúde da população idosa brasileira: um estudo da mortalidade e das internações hospitalares públicas. Informe Epidemiológico do SUS, Porto Alegre, v. 9, n. 1, p. 23-41, 2000.

IBGE. Anuário Estatístico do Brasil. Censo demográfico 2000. Disponível em: <www. ibge.gov.br/home/estatistica/populacao/censo2000>. Acesso em: 28 abr. 2009.
LEITE, M. T. et al. Recursos assistenciais em saúde mental e gerontologia nos municípios de abrangência da 17ª Coordenadoria Regional de Saúde do Estado do Rio Grande do Sul. Relatório de pesquisa, Ijuí, 2003.

RIO GRANDE DO SUL. Estatisticas de Saúde: mortalidade - SIM/2004. Secretaria Estadual de Saúde. Departamento de Ações em Saúde. Núcleo de Informações em Saúde, Porto Alegre, v. 29, 2005.

SILVESTRE, J. A. et al. O envelhecimento populacional brasileiro e o setor saúde. $A r$ quivos de Geriatria e Gerontologia, Rio de Janeiro, v. 10, n. 3, p. 81-89, 1996.

WHO - World Health Organization. Envelhecimento ativo: uma política de saúde. Trad. de Suzana Gontijo. Brasília: Organização Pan-Americana de Saúde, 2005.

\section{Notas}

1 Norma Operacional Básica (NOB). Implementada a partir da criação do Sistema Único de Saúde (SUS), constitui-se de orientações específicas e pactuadas que visam definir melhor a divisão de responsabilidades entre as esferas federal, estadual e municipal; definir critérios para alocar recursos segundo as necessidades da população e integrar os sistemas municipais de saúde.

2 Número de hospitalizações dividido pelo número de habitantes.

3 Número de dias de hospitalização consumido por habitante/ano.

4 Custo de hospitalização demandado por habitante. 